\title{
Sofonisba anguissola, Cindy Sherman: autorretratos
}

\author{
Ligia de Oliveira Barros ${ }^{1}$
}

Resumo: O artigo tem como objetivo apresentar uma análise do processo artístico do autorretrato observando a natureza da representação, da exposição e da construção de uma identidade na produção de duas artistas: a artista renascentista Sofonisba Anguissola (1532-1625) e a artista contemporânea Cindy Sherman (1954), com seus trabalhos performáticos e fotográficos em sua primeira série "Untitled Film Stills". A pesquisa Annateresa Fabris $(2004,2009)$ contribui neste estudo para uma análise das obras com relação a uma visão sociocultural do indivíduo, para, desta forma, comparar as artistas nas suas escolhas e no tratamento do autorretrato.

Palavras-chaves: autorretratos, fotografias, mulheres artistas, renascimento e contemporaneidade, sujeito e pessoa.

Abstrat: This study aims to present an analysis of the artistic process of the self-portrait by observing the nature of representation, exhibition and construction of an identity in the production of two artists: the Renaissance artist Sofonisba Anguissola (1532-1625) and contemporary artist Cindy Sherman (1954), with its performative and photographic in its first "Untitled Film Stills" series. The research Annateresa Fabris $(2004,2009)$ in this study contributes to an analysis of the works in relation to a sociocultural vision of the person, to thereby compare the artists in their choices and in the treatment of self-portrait.

Keywords: self-portraits, photographs, women artists, renaissance and contemporary subject and person.

${ }^{1}$ Graduanda no Curso Superior de Pintura pela Universidade Estadual do Paraná (UNESPAR) campus Escola de Música e Belas Artes (EMBAP). Pesquisadora da Iniciação Científica. E-mail: ligiaobarros@gmail.com. 


\section{Introdução}

Esta pesquisa tem como objetivo o levantamento histórico das obras de Sofonisba Anguissola e Cindy Sherman, verificando a natureza de seus trabalhos quanto à exposição e construção de uma identidade, que se aproxima e distancia da pessoa como ser sociocultural.

Para isso, há necessidade de conhecer e comparar os períodos históricos das obras das duas artistas, bem como analisar as evoluções de tais obras dentro de uma perspectiva baseada na pesquisa de Annateresa Fabris (2004, 2009), que traduz uma visão sociocultural da pessoa inserida numa representação percebida do sujeito enquanto ser biológico, por meio do trabalho pictórico e da fotografia, respectivamente.

Assim, a importância desta pesquisa está em lançar fundamentos para uma futura pesquisa voltada ao retrato e aos autorretratos como linguagens artísticas.

Vale ressaltar que a metodologia utilizada foi a da pesquisa bibliográfica e análise de imagens, que ocorreu por meio da consulta de bancos de dados, sites e ferramentas de pesquisa on-line, todos especializados em arte.

Por fim, como referência para a pesquisa sobre Sofonisba Anguissola foram utilizados os seguintes teóricos: Andrea Bayer (1995), Helen Dore (1996), Izabel Hargrave (2010) e Nina Rahe (2013).

Sobre Cindy Sherman, as pesquisas foram realizadas no site Skarstedt.com e no site do Museu de Arte Moderna de Nova Iorque. 


\section{Autorretratos na História da Arte}

Os egípcios, na Antiguidade, retratavam os faraós e seus séquitos nas paredes das tumbas. Em Roma eram feitos bustos, medalhões e moedas, que demonstravam com muita semelhança a fisionomia da pessoa retratada.

Depois da queda do Império Romano, o retrato ficou no esquecimento durante séculos e foi na Renascença que ele ressurgiu como um instrumento de expressão do Humanismo, em que o homem era o centro do Universo. Inicialmente, o retrato era um artigo de luxo digno de governantes e outros dignitários. Com o surgimento da burguesia, que patrocinou o circuito das artes no período da Renascença, o retrato passou a fazer parte cada vez mais do cotidiano das pessoas como forma de expressão e perpetuação (DORE, 1996).

Os grandes pintores começaram a se especializar nesse tipo de arte, e o retrato passou a ser considerado um símbolo de status, uma expressão de realização pessoal e uma forma de assegurar um lugar na posteridade. Para o artista o retrato representava a chance de alcançar a riqueza e a fama. Pintar um retrato bem-sucedido era muito importante e fazer um autorretrato era especial, pois revelava muito sobre a atitude do pintor em relação à sua obra: "Retratos são evocações da História, pois através deles pode se perceber vestimentas, joias, mobiliários de uma época passada" (DORE, 1996, p. 7).

É bem verdade que um autorretrato não precisa ser necessariamente um retrato. Para Samuel Butler (1835-1902), “Toda obra de um homem, seja em literatura, música, pintura, arquitetura ou em 
qualquer outra coisa, é sempre um auto-retrato; e quanto mais ele tenta se esconder, mais o seu caráter se revelará, contra a sua vontade" (CLIFFORD, [20--], não paginado, tradução nossa); e para Oscar Wilde (1854-1900), "Um retrato pintado com a alma é um retrato, não do modelo, mas do artista" (THE QUOTATIONS PAGE, [20--], não paginado, tradução nossa).

Retornando à Renascença, quando o retrato ressurgiu, se destacam os nomes de grandes mestres da arte: Leonardo Da Vince (1452-1519), Rafael Sanzio (1483-1520), Michelangelo (1475-1564), Donatello (1386-1466), Brunelleschi (1377-1446) e Botticelli (14451510), que indiscutivelmente são mestres na arte do retrato, que buscaram o belo, a perfeição, o estudo da anatomia, da simetria e da proporção das figuras.

Em meio àquela turbulência cultural, segundo Nina Rahe (2013, p. 18), surgiu no inventário da coleção real espanhola, datado de 1582 , uma italiana chamada Sofonisba Anguissola. Pintora da corte da Realeza Espanhola por cerca de 20 anos, ela foi mencionada como excelente retratista, acima de todos os pintores de sua época.

Segundo pesquisa detalhada de Andrea Bayer (1995, p. 201) que também relatou que Sofonisba nasceu em Cremona, Itália entre 1532 e 1538, vivendo até 1625 (as datas de seu nascimento ainda estão incertas, pois ainda existem estudos sobre a verdadeira data) -, ela foi a primeira artista mulher que se tem notícia a adquirir expressiva fama, concebendo trabalhos que foram confundidos com os de Ticiano e Leonardo da Vinci. 
Seu pai Amilcar Anguissola e sua mãe Bianca Ponzoni pertenciam à pequena aristocracia local. Seus pais tinham formação suficiente para se preocuparem com a educação dos seus filhos na área do latim, letras, pintura e instrumentos musicais. Sofonisba e duas irmãs estudaram no atelier de Bernardino Campi (1522-1591) entre os anos de 1550 e 1559 (BAYER, 1995, p. 201).

No período da segunda metade do século XVI, por mais que as mulheres pintoras chegassem a um nível de excelência na técnica e se destacassem na qualidade artística, elas restringiam seus trabalhos a alguns gêneros específicos como a pintura religiosa, a natureza morta e os retratos. Foi neste último gênero que Sofonisba e suas irmãs se concentraram, pintando retratos no âmbito familiar, assim como autorretratos. Ainda hoje há uma dificuldade de atribuir autoria às obras das irmãs, assim como para identificar os modelos retratados. Mas atualmente os estudos das obras destas irmãs estão sendo intensificados, principalmente das obras de Sofonisba (BAYER, 1995, p. 201)

Ainda para Andrea Bayer (1995, p. 202), Sofonisba desenvolveu um estilo à maneira de seu mestre Bernardino Campi, mas realizou uma grande dose de originalidade quanto aos retratos na aplicação da luz, nas cenas, na exploração das texturas e na expressão de seus personagens, ocasionando uma técnica singular.

Sua atuação, no entanto, foi prejudicada pelo surgimento de uma estética que valorizava a relação entre o material e o celestial. Essa dualidade encontrou expressão máxima nas representações do nu feminino e, por ser mulher, Sofonisba jamais poderia realizar tais obras 
sem violar as regras do contexto social vigente (RAHE, 2013, p. 18). Para Chicago e Lucie-Smith (1999), provavelmente não era apropriado para uma mulher usar modelos nus, contudo isso era uma necessidade para aprender a pintar esse tipo de representação.

Assim, a pintora italiana foi a primeira artista mulher conhecida na Europa por seus trabalhos, que serviu de inspiração para muitas outras mulheres se dedicarem à arte, visto que naquela época a pintura era somente praticada por homens.

\section{Tratamento dado às pinturas por Sofonisba}

Para compreender como Sofonisba trabalhava em suas composições é necessário fazer uma análise de seus autorretratos.

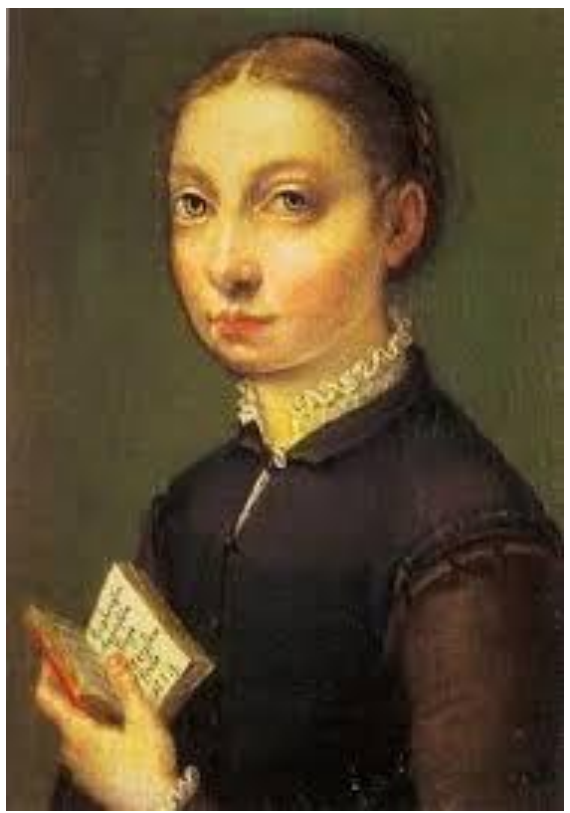

Figura 1 - ANGUISSOLA, S. Autorretrato, 1554.

Óleo s/tela, 19,5x12,5 cm. Kunsthistorisches Museum, Viena. 
Para Hargrave (2010), na figura 1 de 1554 começa a especificidade de Sofonisba em autorretratos. Ela pintou muitos em sua juventude, e neles a artista possui particularidades. Realizado em 1554, esse foi o seu primeiro autorretrato, com um rosto mais frontal, segurando na mão esquerda um pequeno livro com as seguintes inscrições "Sofonisba Anguissola, solteira, fez a si mesma em 1554". A artista, ao mostrar o pequeno livro, demonstra a sua educação literária e na inscrição ela se revela como pintora (HARGRAVE, 2010, p. 214).

Para Perlingieri (1992), ela olha para o espectador com um olhar desafiador. Já para Chicago e Lucie-Smith (1999), o livro que ela segura é um sinal de sua inteligência e sucesso. Nas inscrições na tela, Sofonisba se refere a uma crítica às teorias de Aristóteles, dizendo que nunca pertenceu a nenhum homem e que nunca deu à luz a uma criança (PERLINGIERI, 1992). 


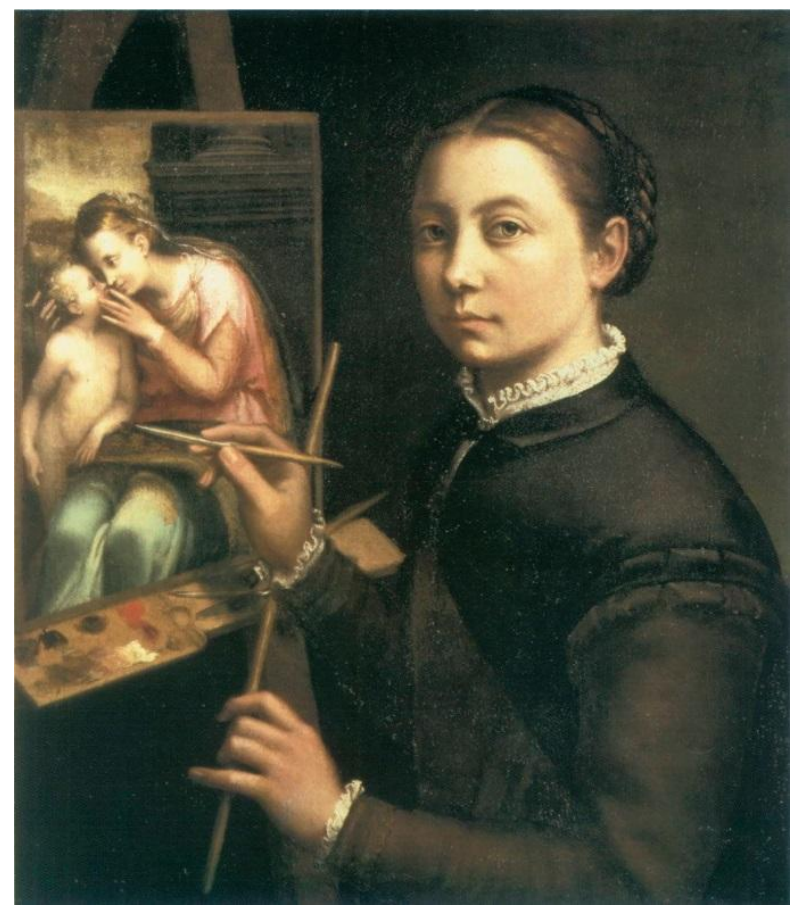

Figura 2 - ANGUISSOLA, S. Autorretrato com cavalete, 1556. Óleo s/tela, 66x57cm, Museum Zamek, Lancut, Polônia.

Dois anos depois do primeiro autorretrato em 1556, como mostra a figura 2, Sofonisba se retrata como pintora no ato de pintar, é modelo e ao mesmo tempo artista. Esse quadro tem como tema a própria arte testemunhando sua época.

A tela tem um fundo neutro e ela está diante de um cavalete em que pinta uma madona com um menino e afasta o pincel da tela para olhar o espectador, que é o espelho em que ela se observa. Nesse trabalho, pode-se observar seu domínio técnico com relação à luz, quando ela destaca o ponto de luz na testa, na maçã do rosto e na ponta do nariz no lado esquerdo de sua face, ao passo que no outro lado deixa sombreado, 
com o reflexo de luz contornando o lado esquerdo, dando volume ao rosto. Os olhos ainda são representados grandes e redondos, mas não estão exagerados como no autorretrato de 1554 (HARGRAVE, 2010, p. 214).

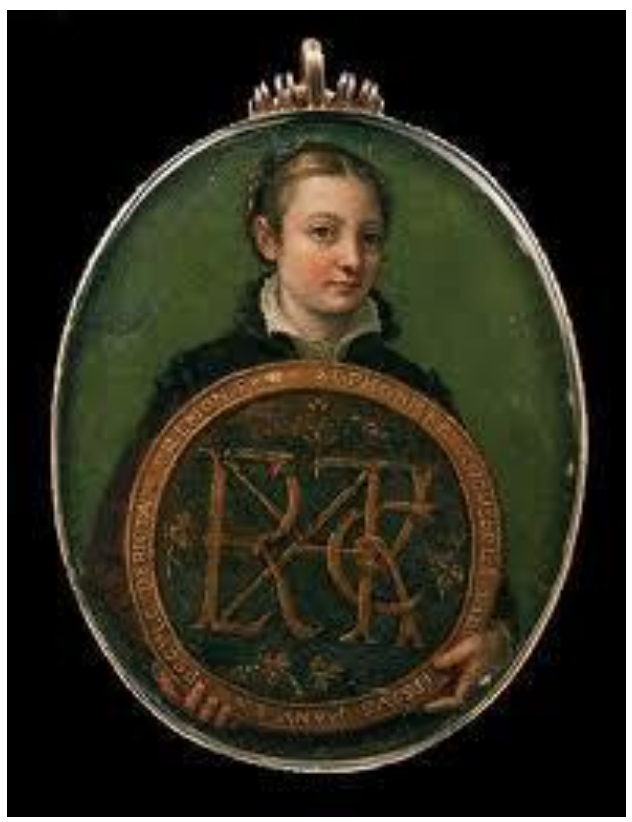

Figura 3 - ANGUISSOLA, S. Autorretrato, 1556.

Óleo s/metal, 8,3x6,4cm, Museum of Fine Arts, Boston.

Com referência à figura 3, autorretrato de 1556, Sofonisba foi bastante criativa, usou o metal como suporte e inovou transformando uma pequena medalha de brasão ao tamanho de um escudo com letras sobrepostas com iniciais dos nomes de seus familiares e da cidade natal (HARGRAVE, 2010, p. 215).

Nessa fase a artista pode mostrar sua interpretação do mundo feminino transformando o brasão em escudo, com o qual ela se protege 
das limitações impostas às mulheres de sua época, podendo, desta forma, protegida pela importância de seu nome, transgredir e pensar sua arte.

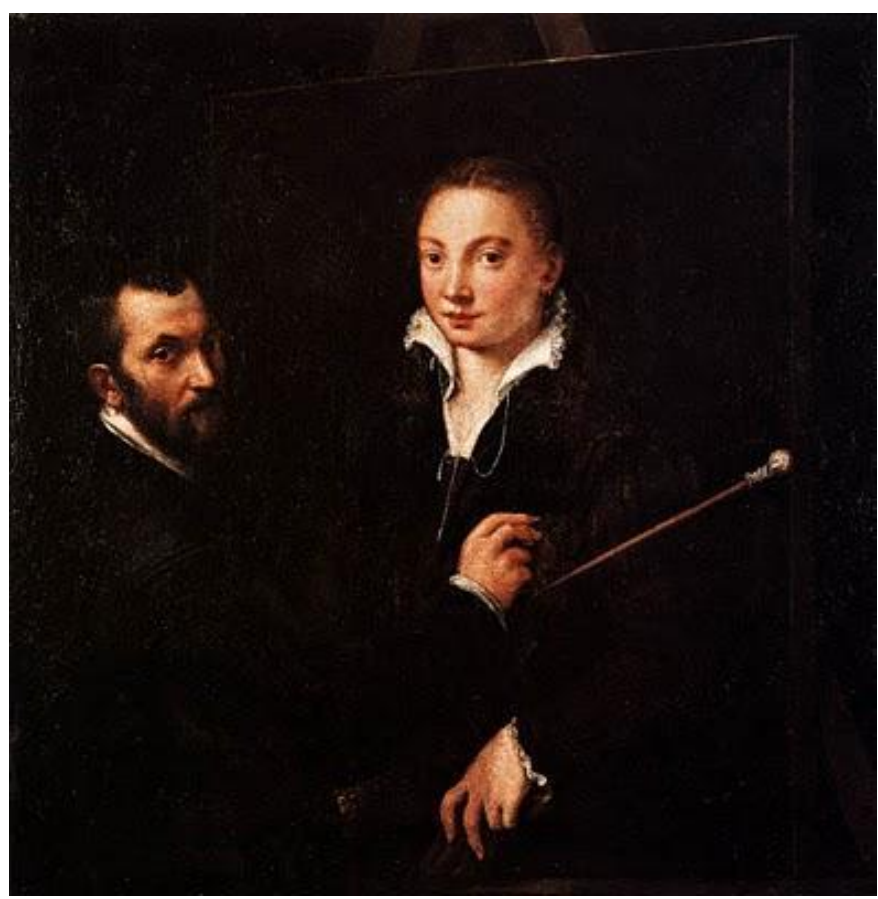

Figura 4 - ANGUISSOLA, S. Bernardino Campi, 1559.

Óleo s/tela. Pintando Sofonisba Anguissola.

Segundo Isabel Hargrave, em 1559, devido à fama de Sofonisba, o rei Felipe II da Espanha a convida para ser dama de companhia da futura rainha Isabel de Valois, sua terceira esposa. Antes de partir para a Espanha Sofonisba pinta o seu autorretrato mais interessante, figura 4, intitulado "Anguissola, S.Bernardino Campi” de 1559. No quadro está representando seu mestre, Bernardino Campi pintando sua aluna Sofonisba, que na verdade é um autorretrato daquela que foi pintada na obra. As figuras do retrato parecem estar na mesma realidade, os fundos 
das duas telas são igualmente neutros, a diferença são as linhas que demarcam os limites da tela dentro da tela. Nessa obra, Sofonisba atesta o aval e a relação que mantinha com seu mestre, que como pintor renomado the ofereceu um papel importante e um espaço na arte, demonstrando sua proximidade até mesmo na técnica artística.

$\mathrm{Na}$ corte espanhola, Sofonisba foi tutora de pintura, o que demonstra que foi permitido que ela trabalhasse desta forma, mesmo numa época em que valores cerceavam os direitos das mulheres. Portanto restringiu o seu trabalho artístico, nesse período, à arte retratista dos membros da corte, no entanto, Sofonisba não trabalhava oficialmente como pintora, por isso muito de seus quadros não são datados, nem assinados e também foram muito copiados por outros retratistas contemporâneos da corte, como Allonso Sánchez Coelho, Jorge de la Rua, Anthonis Moro e até por Rubens, anos mais tarde (HARGRAVE, 2010, p. 216).

Após a morte de Izabel de Valois, Sofonisba ainda permaneceu cerca de seis anos na corte, quando se casou com um membro de uma família nobre da Sicília, Fabrício Moncada, que morreu em 1575, foi quando Sofonisba resolveu voltar para Cremona. Nesta viagem de retorno a sua cidade natal conheceu Orazio Llomelino, capitão do navio, com quem se casou novamente. Nos seus últimos anos a pintora viveu entre Gênova e Palermo. Sua casa foi sempre frequentada por certa intelectualidade local, e ela permaneceu pintando e talvez lecionando pintura por muito tempo (HARGRAVE, 2010, p. 217). 
Sofonisba foi uma mulher visionária e com muita criatividade trabalhou os retratos e autorretratos. No entanto, ela, como muitas outras artistas mulheres, ficou esquecida na História da Arte, felizmente alguns estudiosos se voltaram ao estudo das suas obras. Isto porque a História da Arte ocidental apoiada em dogmas etnocêntricos têm privilegiado artistas brancos, homens e de determinada classe social.

\section{$O$ retrato com o advento da fotografia}

$\mathrm{O}$ retrato ${ }^{1}$, durante o século $\mathrm{XV}$, não era somente um deleite para a nobreza, outros grupos sociais também usufruíram desta arte, como comerciantes, artesãos, banqueiros, sábios humanistas e artistas. Esta arte retratista pictórica foi constante nas classes mais abastadas, e o autorretrato era a forma de muitos artistas serem lembrados, além de servir para demonstrar sua habilidade artística.

Contudo, o retrato pictórico de seres humanos é contínuo somente até o advento da fotografia no século XIX. Esta invenção foi revolucionária para a história da humanidade. O novo processo, que se desenvolveu intermitentemente na história, por meio de saltos e longos intervalos, na tentativa de aperfeiçoar métodos de impressão sobre o papel, foi, primeiramente, dominado pelos chineses e mais tarde foi difundido na Europa (AMAR, 2011).

Segundo Walter Benjamim (1994, p. 167):

\footnotetext{
${ }^{1} \mathrm{O}$ historiógrafo e teórico da arte André Félibien foi quem pela primeira vez sugeriu o termo retrato para o uso exclusivo da representação pictórica de seres humanos, ficando a expressão figurativa para a pintura de animais.
} 
Pela primeira vez houve no processo de reprodução da imagem, a mão foi liberada das responsabilidades artísticas mais importantes, que a partir da fotografia cabiam unicamente ao olho. Como o olho apreende mais depressa do que a mão desenha, o processo de reprodução das imagens experimentou tal aceleração que começou a situar-se no mesmo nível que a palavra oral.

Assim sendo, certamente com o advento da fotografia a questão do retrato ficou voltada à máquina fotográfica, pois esta pode ser mais fiel do que um retrato pictórico. Até a chegada da invenção da fotografia, a arte tinha como essência a mimese como característica suficiente para conceituar uma obra de arte. A partir do momento em que o artista se viu livre para criar sua própria realidade dentro de um novo conceito de arte eclodiram trabalhos bastante criativos e admiráveis.

Tendo em vista tal afirmação, Annateresa Fabris (2009, p. 57) comenta que com a fotografia o retrato passa a ser o seu principal tema pela capacidade dela captar com maior veracidade a fisionomia humana. Além disso, permite ainda a multiplicação da identidade, que se torna ubíqua e, deste modo, pode estar em vários lugares. Também se verifica na fotografia a "semelhança" e a "diferença", ambas compostas em um retrato, pois poderá haver a unicidade da pessoa na multiplicidade dos sujeitos, isto é, personagens com traços de outros modelos, e também quanto à multiplicidade das pessoas na unicidade do sujeito, ou seja, as diferentes máscaras que um retratado pode assumir. 


\section{Autorretrato na fotografia como linguagem artística}

Dentro dessa perspectiva, surge a artista norte-americana Cindy Sherman, que a partir da primeira metade dos anos de 1970 problematiza a noção de autorretrato, quando trabalha artisticamente fotos em que ela encarna diferentes personagens utilizando artifícios para montar tais figuras dramáticas. E, ao mesmo tempo, se utiliza da veracidade da fotografia criando novos personagens.

Cindy Sherman nasceu em Glen Ridge, Nova Jersey, em 1954, e em 1976 se formou em arte na Faculdade Estadual de Buffalo, em Nova York. Desde o início de sua carreira, Sherman esteve focada na fotografia como seu principal meio de expressão. Ela é amplamente conhecida por suas fotografias e filmes reflexivos, nos quais se faz passar por uma variedade de personagens que questionam sobre a condição feminina e os estereótipos que limitam o papel da mulher na sociedade e na cultura (SKARSTEDT, 2014).

Uma das mais famosas séries de Sherman é a "Untitled Film Stills" $(1979)^{2}$, que pode ser traduzida como "Fotografia de Cena, sem Título" ou "Stills Cinematográficos sem títulos", em que ela trabalhou caracteres em preto e branco, tendo como inspiração as imagens de mulheres apresentadas pelo cinema ao longo dos anos de 1950 e 1960. $\mathrm{Na}$ série a artista problematiza a identidade feminina no processo de

\footnotetext{
${ }^{2}$ Em dezembro de 1995, o Museu de Arte Moderna de Nova York (2014) adquiriu todas as fotografias em preto e branco da série "Untitled Film Stills", tornando toda coleção pública em um único espaço, já que a série havia sido exibida em sua totalidade somente uma vez antes de ser adquirida pelo Museu de Arte Moderna de Nova York.
} 
identificação na sociedade, na definição de papéis sexuais e sociais predeterminados (WEB EXHIBITS, 2014).

"Untitled Film Stills" foi a sua primeira série realizada entre os anos de 1977 e 1980. É uma crítica feminista em relação ao cinema, especificamente de Hollywood, em que as imagens das mulheres eram estereotipadas. Nesse trabalho, a artista recorre a um imaginário cinematográfico, transforma-se em diferentes personagens como atriz, namorada, estudante, dona de casa, moça do interior na cidade grande, sedutora, esportista, desamparada, sofredora, vizinha, etc. Alguns personagens são mais trabalhados, construindo minisséries dentro de uma série maior (SKARSTEDT, 2014).

Mais tarde, Sherman começou a trabalhar com imagens coloridas e continuou criando séries sobre diferentes temas como a sexualidade, o perverso, as fantásticas e até retratos feitos no estilo dos antigos mestres, que convidam o espectador a interpretar narrativas estranhas que sempre giram em torno do sexo feminino e do papel que a mulher desempenha dentro da nossa cultura (WEB EXHIBITS, 2014).

A série é também muito interessante com relação à questão do conceito de autorretrato, por isso foi eleita para este estudo. Sherman não usou muita maquiagem e nem máscaras, deixando o rosto visível, conservando sua fisionomia. Seus artifícios foram praticamente de vestinômico, com a utilização de roupas de brechós.

Na série, Sherman é a modelo e ao mesmo tempo a fotógrafa de suas encenações; mas, segundo a artista, não são autorretratos em um sentido tradicional. "Usando chapéus, maquilagem e diferentes tipos de 
penteados, Cindy Sherman problematiza a noção de auto-retrato na medida em que encarna diferentes personagens graças a tais artifícios" (FABRIS, 2004, p. 58).

Sobre a questão da intenção da artista em não se autorretratar, disse ela numa entrevista à Mark Stevens em sete de abril de 2008: "Eu realmente não acho que eles são sobre mim, talvez eu esteja querendo ser todos esses personagens. Ou pelo menos tentar" (MUSEU DE ARTE MODERNA, 2014, não paginado, tradução nossa).

Sherman começou a fazer as fotos em 1977 aos vinte e três anos. As seis primeiras fotos foram uma experiência em que ela se produziu no papel de uma atriz loura imaginária. As fotografias, todas em preto e branco, parecem com cenas de filmes num cartaz para publicidade.

É necessário descrever as seis fotografias para demonstrar a capacidade da artista em criar momentos de cenas intrigantes, em que a artista utiliza seu corpo como suporte para questionar o estereótipo da mulher imposto pelo cinema e pelo olhar masculino, tornando a mulher objeto de admiração. As fotografias estão no site do Museu de Arte Moderna de Nova Iorque:

A primeira foto, Untitled Film Still-1, se refere a uma mulher jovem, loura e com cabelos curtos; a mesma está num corredor e se apresenta de costas adentrando em uma sala, onde a porta já se encontrava aberta; ela fica em frente à porta e olha para o lado como se estivesse vendo ou ouvindo algo a se aproximar, na mão esquerda possui óculos 
que acabara de tirar. A sombra do corpo da moça, que reflete na parede, oferece um ar de mistério ${ }^{3}$.

Untitled Film Still-2, uma moça jovem, magra, sensual, loura e bela, admirando sua beleza e sensualidade ao sair do banho. Ela se representa duplamente, na fotografia e no espelho. Ela está numa posição de perfil em relação ao observador, com a cabeça virada para o espelho, no qual se reflete e cobre seu corpo com uma toalha, denunciando sua nudez. A solidão é quebrada pelos objetos pessoais deixados no lavabo.

Untitled Film Still-3 exibe uma jovem, loura com cabelo chanel. Ela está usando um avental e está diante de um balcão de cozinha, onde se vê vários utensílios domésticos, entre eles há somente uma caneca em primeiro plano. A posição de seu corpo é de lado e seu rosto está de frente para o observador, seu olhar pensativo e entediado, o braço esquerdo se apoia no balcão e o outro com a mão no estômago, confirmando uma situação questionadora.

Untitled Film Still-4, a moça de taier e casaco de inverno, demonstra desalento e sofrimento, ao estar encostada na porta fechada em um corredor sombrio, buscando ouvir uma resposta de alguém que possivelmente estivesse no apartamento.

Untitled Film Still-5 mostra uma mulher jovem com uma carta na mão, que estava sendo lida e que está dialogando com o olhar com outro provável personagem presente na cena, porém não visualizado. Sua expressão sugere um desacordo com a notícia trazida pela carta.

\footnotetext{
${ }^{3}$ A publicação das seis fotos da série Untitled Films Stills da artista Cindy Sherman não foi possível em razão da Lei n.9.610 de 19 de fevereiro de 1998.
} 
Untitled Film Still-6 é uma das mais belas fotos desta primeira série; a moça, linda de cabelos curtos e louros, está deitada sensualíssima em uma cama desarrumada, a perna direita está inclinada revelando um corpo bonito. Com roupas íntimas e um espelho na mão, um objeto que representa o autorretrato, que reflete a imagem tão moldada dos desejos femininos na busca de uma aprovação do olhar masculino. Transmite sentimentos de paixão e volúpia.

Em 1995, o Museu de Arte Moderna de Nova Iorque, por meio do curador-chefe do Departamento de Fotografia do Museu, Peter Galassi, organizou e selecionou a série "Untitled Film Stills".

Segundo Galassi, foram muitos os artistas que deixaram sua marca na história da arte americana, mas Sherman visualizou uma estratégia inovadora. Gallassi acredita que para ela a imagem da cultura pop não foi apenas um tema como foi para Walker Evans ou matériaprima para Andy Warhol, e sim um vocabulário artístico inteiro na utilização do ready-made (MUSEU DE ARTE MODERNA, 2014). Galassi ainda relata que as fotos de Sherman inspiradas em filmes funcionam como verdadeiras glossies de oito por dez polegadas que serviam para atrair o público para um drama muito atraente e irreal.

Nos "Untitled Film Stills" não existe uma grande personagem feminina, mas mulheres estereotipadas e também a inexistência da figura masculina. As sessenta e nove heroínas solitárias mapearam uma constelação particular de feminilidade fictícia que tomou conta do pósguerra na América, período da juventude de Sherman, e esta fase foi o marco zero da mitologia contemporânea. Ao encontrar uma forma para 
sua própria sensibilidade Sherman tocou sensivelmente o público em geral. Embora a maioria das personagens seja inventada, sentimos imediatamente algo familiar e isso é o que torna o trabalho de Sherman bastante atraente e mostra o quanto ela se empenha em se transformar nos seus personagens (GALASSI, 1995, apud MUSEU DE ARTE MODERNA, 2014).

Duas mulheres artistas em diferentes momentos da História da Arte, Sofonisba Anguissola na Renascença e Cindy Sherman na Contemporaneidade, questionam a situação da mulher na sociedade e até nos momentos atuais este tema é frequente, isto representa que a experiência feminina foi sempre negligenciada e desvalorizada, assinalando as desigualdades entre homens e mulheres e revela a opressão patriarcal e os artifícios de ocultamento da mulher na sociedade.

\section{Conclusão}

As ideias e as obras comentadas das duas artistas têm como objetivo de verificar as semelhanças e as diferenças entre elas. Não há afinidade nas questões formais e nem na linguagem artística, pois viveram em épocas diferentes, no entanto, tiveram discursos parecidos e participaram ativamente de momentos importantes da arte.

Sofonisba Anguissola, quando pintou seus autorretratos compostos em óleo sobre tela, com técnicas renascentistas como a primatura, o esfumato e a velatura -, principalmente as obras descritas neste estudo, representou algo mais que sua habilidade de pintar, concretizou o fisionômico e o vestinômico, trazendo a sua pessoa 
produzida culturalmente e socialmente na busca de uma verossimilhança, na construção de uma identidade, valorizando sua personalidade. Empenhou-se na sua habilidade, criatividade, inteligência, intelectualidade, seu amor pela família e na utilização de objetos significativos para sua representação e exposição diante dos fatos e da realidade em que ela se encontrava.

Como a história nos revela, as mulheres tinham limitações para se expressar em seus trabalhos artísticos e Sofonisba soube aproveitar todos os recursos que tinha para edificar a natureza da representação e exposição de suas obras, aproximando o sujeito da pessoa, ou melhor, promovendo o encontro da visão sociológica da pessoa e da representação do sujeito, o ser biológico, seu corpo físico.

Cindy Sherman, por sua vez, se mostrou uma verdadeira atriz, pois tentou desconstruir sua personalidade, se empenhou na busca da dessemelhança no ato da pose, emprestando seu corpo como suporte, empregando artifícios na roupagem, maquiagem (vestinômico), para construir outra identidade, outra pessoa. Afastando de si o "sujeito" e aproximando de uma "pessoa" culturalmente, socialmente diferente do seu ser natural. Mesmo não pretendendo se autorretratar ela ainda se permite ser reconhecida nas suas fisionomias, nessa primeira série especificamente.

Ainda sobre a série em questão, verificamos que a artista mesmo na busca de tal dessemelhança ainda possui certa aproximação com as personagens, esta situação põe em questão o autorretrato, que ela tanto negou. Foi quando, na véspera da exposição de um novo trabalho no 
Metrô de Nova York, alguns artistas foram convidados para uma entrevista e Calvin Tomkins, autor e crítico de arte da The New Walker, fez a seguinte pergunta a Sherman:

Calvin Tomkins: Qual dos "Untitled Film Still" mais se aproxima do real de Cindy Sherman? Cindy Sherman: O "choro" Untitled Film Still, n. ${ }^{\circ}$ 27, de 1979. Não é porque eu sou uma pessoa triste, eu não sou, mas porque em todos os outros estou levantando uma autoconsciência (pensamento, por vezes, de forma reflexiva), e a menina chorando tem essa camada aparente, mostrando uma vulnerabilidade que eu me apresento (TOMKINS, [20--], não paginado, tradução nossa).

Nesse momento, Sherman se mostra bastante representada nas suas fotos. E, desta forma, podemos concluir que Sherman, nesta primeira série, ainda mostrava um pouco de sua personalidade na representação e na exposição, diferente do que acontecerá em seus futuros trabalhos.

Assim, despontam na pesquisa dois momentos da História da Arte em que o autorretrato é empregado com intenções diferentes, mesmo assim, em ambos, há sempre a preocupação em mostrar o papel da mulher.

Na construção de uma identidade, Sofonisba usa sua habilidade artística para mostrar seu fisionômico, isto é, fazer com que o observador, seu público, a veja como ela realmente queria ser vista. Esta intenção é completada pelo vestinômico, acessórios e objetos que eram utilizados no seu contexto histórico, também questionando a imagem estereotipada da mulher. 
Quanto às diferenças com relação à construção da identidade, Sofonisba pretendia se mostrar enquanto Sherman se escondia em suas personagens. Sofonisba Anguissola, na Renascença, uma mulher diferenciada do seu tempo, tinha princípios que tendiam ao feminismo ${ }^{4}$. $\mathrm{Na}$ contemporaneidade, Cindy Sherman, mesmo sem se intitular feminista ${ }^{5}$, critica a imagem da mulher como produto do olhar masculino.

Posto isso, vale ressaltar que essas artistas foram escolhidas para este estudo por terem semelhanças com relação à questão de gênero e ambas se autorretrataram com o objetivo de representar o feminino, o comportamento da mulher na sociedade, a autoafirmação e a conquista do seu espaço no mundo e, desta forma, desempenhando o papel de artista.

\section{Referências}

AMAR, P.-J. História da Fotografia. 2. ed. Lisboa: Edições 70, 2011.

BAYER, A. Sofonisba Anguissola and her sisters. Cremona, Viena and Washington. The Burlington Magazine, v. 13, n. 1104, p. 201-202, Mar. 1995.

BEnjamin, W. Magia e Técnica, Arte e Política: Ensaios sobre literatura e História da Cultura. São Paulo: Brasiliense, 1994.

BLOG OF AN ART ADMIRER. Italian Renaissance Painter Sofonisba Anguissola (1532-1625). Disponível em: <http://www.artistsandart.org/2010/01/italian-renaissance-paintersofonisba.html>. Acesso em: 10/01/2014.

\footnotetext{
${ }^{4}$ Movimento que combate a desigualdade de direitos entre mulheres e homens.

${ }^{5}$ Pessoa simpatizante ou partidária do feminismo.
} 
CHICAGO, J.; LUCIE-SMITH, E. Womem and Art: Contested Territory. New York: The Ivy Press Limited, 1999.

CLIFFORD, D. Samuel Butler (1835-1902). The Victorian Web. [20-]. Disponível em: <http://www.victorianweb.org/science/butler.html>. Acesso em: 20/01/2014.

DANTO, A. C. The Art world. The Jornal of Philosophy, v. 61, n. 19, p. 571-584, Out. 1964.

DORE, H. A arte dos retratos. Rio de Janeiro: Ediouro, 1996.

FABRIS, A. A pose pausada. In: Fotografia e arredores. Florianópolis, SC: Letras Contemporâneas, 2009.

. Identidades Virtuais: Uma Leitura do retrato fotográfico. Belo Horizonte, MG: Editora UFMG, 2004.

FERRO, I. F. Cindy Sherman e a Crítica da Representação da Mulher pelo Cinema Hollywoodiano. $46 \mathrm{f}$. Monografia (Curso de Educação Artística) - Universidade Federal do Paraná, Curitiba, PR, 2010.

HARGRAVE, I. Sofonisba Anguissola (1532/38-1625): Uma pintora no Renascimento Espanhol. Campinas, SP: Unicamp, 2010.

JACOBS, F. Woman's Capacity to Create: The Unusual Case of Sofonisba Anguissola. Renaissance Quarterly, v. 47, n. 1, p. 74-101, Spring 1994.

KUSCHE, M. Sofonisba Anguissola retratista de la corte española. Paragone - arte, Anno XLIII, n. 34-35, 509-511, p. 3-34, 1992.

. Sofonisba Anguissola vuelta a Italia. Continuación com la corte española. Paragone - arte, Anno XLIII, n. 41, 513, p. 10-35, 1992.

MUSEU DE ARTE MODERNA de Nova York. 2014. Disponível em: <http://www.moma.org/interactives/exhibitions/1997/sherman/>. Acesso em: 24/01/2014. 
PERLINGIERI, I. S. Sofonisba Anguissola: The First Great Woman Artist of the Artist of the Renaissance. In: HARRIS, A. S. Painting a flawed portrait. The Women's Review of Books, New York: Rizzoli, v.10, n. 2, 1992.

. Sofonisba Anguissola's Early Sketches. Woman's Art Journal, v. 9, n. 2, p. 20-21, Autumn 1988/Winter 1989.

PITTOLO, V. Cindy Sherman born 1954. Artist biography. Tate. Disponível em: <www.tate.org.uk/art/artists/cindy-sherman-1938>. Acesso em: 25/04/2014.

RAHE, N. Mulheres ainda são minoria na arte?. Bravo, São Paulo, v. 189, Maio 2013.

SKARSTEDT. Cindy Sherman. 2014. Disponível em: <http://www.skarstedt.com/artists/cindy-sherman/>. Acesso em: 20/01/2014.

STEVENS, M. How I Made It: Cindy Sherman on Her 'Untitled Film Stills'. New York Magazine, Apr. 2008. Disponível em: <http://nymag.com/anniversary/40th/culture/45773/>. Acesso em: $12 / 04 / 2014$.

THE QUOTATIONS PAGE. Oscar Wilde. [20--]. Disponível em: $<\mathrm{http} / / / \mathrm{www}$.quotationspage.com/quotes/Oscar_Wilde>. Acesso em: 20/01/2014.

TOMKINS, C. Art Cindy Sherman. Interview Magazine. [20--]. Disponível em: <http://www.interviewmagazine.com/art/cindysherman/\#_>. Acesso em: 10/02/2014.

WEB EXHIBITS. Cindy Sherman's Untitled Film Stills. 2014. Disponível em: <http://www.webexhibits.org/colorart/sherman.html>. Acesso em: 24/01/2014. 